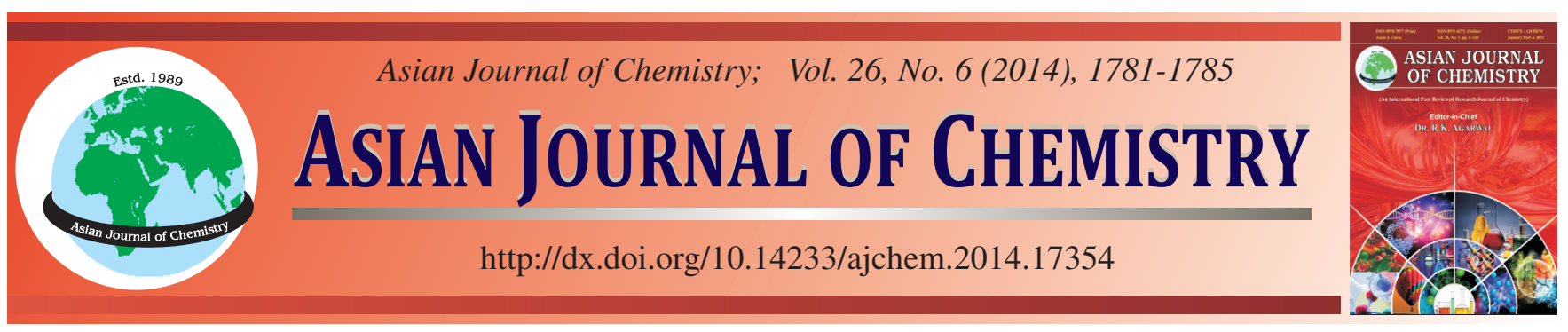

\title{
A New Pyrene Derivative Based on $\Lambda$-Shaped Tröger's Base for Non-Doped Organic Blue Light-Emitting Diodes $\dagger$
}

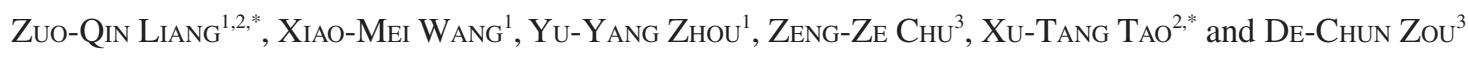

${ }^{1}$ Jiangsu Key Laboratory for Environment Functional Materials, School of Chemistry Biology and Material Engineering, Suzhou University of Science and Technology, Suzhou 215009, P.R. China

${ }^{2}$ State Key Laboratory of Crystal Materials, Shandong University, Jinan 250100, P.R. China

${ }^{3}$ Department of Polymer Science and Engineering, College of Chemistry, Peking University, Beijing 100871, P.R. China

*Corresponding authors: E-mail: zuoqinliang@mail.usts.edu.cn; txt@icm.sdu.edu.cn

A novel pyrene derivative, 2,8-di(1-pyrenyl)-6H,12H-5,11-methanodibenzo[b,f][1,5]diazocine (TBPy), was synthesized and well characterized. The structure was confirmed with ${ }^{1} \mathrm{H}$ NMR, ${ }^{13} \mathrm{C}$ NMR and MS analyses. Its photophysical, thermal, electrochemical and electroluminescent properties as well as the electronic structure were investigated. The compound shows good thermal stability, high fluorescence yield and high hole-transport ability. The organic light-emitting diode using TBPy as an emitter layer exhibits a blue emission at $485 \mathrm{~nm}$. Therefore, it is a promising candidate for fabricating efficient blue organic light-emitting diodes.

Keywords: Pyrene, Tröger's base, $\Lambda$-Shaped, Organic light-emitting diodes.

\section{INTRODUCTION}

Since the first reported by Tang and VanSlyke ${ }^{1}$, organic light-emitting diodes (OLEDs) have gained industrial acceptance and been successfully used for flat-panel displays and solid-state lightings ${ }^{2-5}$. In these applications, good blue-emitting materials and devices have been essential ${ }^{6}$ and therefore there have been continual efforts towards exploring blue-emitting materials and devices with improved characteristics. Among various emitting materials, pyrene is a potentially good candidate for blue OLED applications due to its high photoluminescence (PL) quantum yield, excellent thermal stability and high charge carrier mobility $^{7-9}$. However, the performances of pyrene as blue emitters have been hampered by the tendency to form $\pi$ aggregates/excimers in solid state, resulting to long-wavelength $\pi$ aggregates/excimers emission with low fluorescence quantum yield ${ }^{10}$.

Chemical structure of the molecules can affect their optical properties, especially in solid state. To construct a non-coplanar or spiro-molecular configuration is believed necessary to gain high fluorescence quantum yield in solid state ${ }^{11-14}$. Compounds with such kinds of non-coplanar configurations can weaken intermolecular $\pi-\pi$ interactions and thus effectively alleviate fluorescence quenching in solid state. Tröger's base (TB), an old compound with more than 100 years' history ${ }^{15}$, has gained steady interest in recent years because of its $\mathrm{C}_{2}$ symmetry, particular rigid and concave $\Lambda$-shaped framework ${ }^{16-19}$. The $\Lambda$ shaped twisted configuration is advantageous for the suppression of intermolecular $\pi-\pi$ close stacking. In recent years, our group has successfully constructed a series of Tröger's base derivatives and studied their optoelectronic properties ${ }^{20-23}$. Fluorene and anthracene derivatives based on Tröger's base showed strong fluorescence both in dilute solutions and aggregate states $^{21}$. Moreover, $\Lambda$-shaped pyridinium salts exhibited a special aggregation-induced emission property ${ }^{22}$. Encouraged by their excellent photoluminescence properties, we designed and synthesized a pyrene derivative based on Tröger's base to exploit its potential as a blue-emitting material in this paper. Herein, we present the synthesis, photophysical, electrochemical, thermal and electroluminescent (EL) properties of the pyrene derivative based on Tröger's base.

\section{EXPERIMENTAL}

All solvents used for the measurements were further purified. Dry dichloromethane and tetrahydrofuran (THF) were freshly distilled over calcium hydride and sodium prior to use,

†resented at The 7th International Conference on Multi-functional Materials and Applications, held on 22-24 November 2013, Anhui University of Science \& Technology, Huainan, Anhui Province, P.R. China 
respectively. The ${ }^{1} \mathrm{H}$ and ${ }^{13} \mathrm{C}$ NMR spectra were recorded at $25^{\circ} \mathrm{C}$ using a Bruker Avance 300 or $400 \mathrm{MHz}$ spectrometer. Mass spectrum was determined with an AXIMA-CFR plus MALDI-TOF mass spectrograph. UV-visible absorption spectra were recorded on Varian Cary 50 spectrophotometer. Fluorescence measurements were carried out with a Hitachi F-4500 fluorescence spectrometer equipped with a $150 \mathrm{~W}$ Xe lamp. The fluorescence quantum yield in thin film state was determined by an integrating sphere connected to a spectrophotometer. Thermal gravimetric analysis (TGA) and differential scanning calorimetry (DSC) measurements were carried out under a nitrogen atmosphere with a Perkin-Elmer Diamond thermogravimetric analyzer and a Perkin-Elmer Diamond DSC thermal analysis system, respectively. Cyclic voltammetry was performed on a CHI660B electrochemical work station in dry dichloromethane using $\mathrm{Bu}_{4} \mathrm{NClO}_{4}(0.1 \mathrm{M})$ as supporting electrolyte with a scan rate of $50 \mathrm{mV} / \mathrm{s}$ at room temperature under argon. A platinum wire was used as a counter electrode, glassy carbon as a working electrode and $\mathrm{Ag} / \mathrm{Ag}^{+}(0.1 \mathrm{M}$ of $\mathrm{AgNO}_{3}$ in acetonitrile) as a reference electrode. The $\mathrm{Ag} / \mathrm{Ag}^{+}$ reference electrode was calibrated by running cyclic voltammetry on ferrocene as the internal standard.

Organic light-emitting diode fabrication and characterization: The device was fabricated with the configuration ITO/PEDOT:PSS (50 nm)/TBPy (50 nm)/TPBI(15 nm)/LiF(1 $\mathrm{nm}) / \mathrm{Al}(80 \mathrm{~nm})$. The patterned ITO substrate was carefully cleaned sequentially by detergent, deionized water and acetone and finally treated with UV-ozone for $25 \mathrm{~min}$. PEDOT:PSS was spin-coated on the precleaned ITO substrate and dried by baking in air at $120{ }^{\circ} \mathrm{C}$ for $2 \mathrm{~h}$, then TBPy was spin-casted from chloroform solution $(5 \mathrm{mg} / \mathrm{mL})$. TPBI and the metal electrode were deposited on the ITO substrate by thermal evaporation under a vacuum of $10^{-6}$ Torr. The deposition rates were $2-3 \AA /$ s for TPBI and 5-7 $\AA$ /s for the metal cathode. The emitting area was $2 \mathrm{~mm} \times 2 \mathrm{~mm}$. The electroluminescent spectra were measured with a spectrofluorometer FP-6200 (JASCO).

\section{Synthesis}

2,8-Dibromo-6H,12H-5,11-methanodibenzo[b,f][1,5]diazocine (1): At $-15^{\circ} \mathrm{C}, 80 \mathrm{~mL}$ trifluoracetic acid was slowly added to the mixture containing 4-bromobenzenamine $(6.88$ $\mathrm{g}, 40.0 \mathrm{mmol})$ and paraformaldehyde $(2.39 \mathrm{~g}, 80.0 \mathrm{mmol})$. After complete addition, the mixture was allowed to warm to room temperature and stirring was continued for 6 days. The mixture was diluted with ice water and alkalinized by concentrated aqueous ammonia. The solution was extracted with dichloromethane. The organic layer was washed with water and saturated brine, dried over anhydrous $\mathrm{MgSO}_{4}$. After the solvent was removed, the crude product was chromatographed on silica gel using petroleum/ethyl acetate $(\mathrm{v} / \mathrm{v}=5: 1)$ as eluent, to give a light yellow solid $5.30 \mathrm{~g}$. Yield: $69.7 \%$. ${ }^{1} \mathrm{H}$ NMR $\left(\mathrm{CDCl}_{3}, 400 \mathrm{MHz}, \mathrm{ppm}\right), \delta: 4.10$ (d, 2H, $\left.J=16.8 \mathrm{~Hz}\right), 4.27$ (s, $2 \mathrm{H}), 4.65(\mathrm{~d}, 2 \mathrm{H}, J=16.8 \mathrm{~Hz}), 7.01-7.06(\mathrm{~m}, 4 \mathrm{H}), 7.26-7.30$ $(\mathrm{m}, 2 \mathrm{H})$.

2,8-(6H,12H-5,11-Methanodibenzo[b,f]diazocineylene)diboronic acid (2): Under $\mathrm{N}_{2}$ atmosphere at $-78^{\circ} \mathrm{C}, 2.5 \mathrm{M}$ $n$-BuLi (4.80 mL, $12.0 \mathrm{mmol})$ was added to a mixture of compound $1(1.88 \mathrm{~g}, 5.00 \mathrm{mmol})$ and $20 \mathrm{~mL}$ dried THF. The reaction mixture was stirred for $1 \mathrm{~h}$ at $-78^{\circ} \mathrm{C}$ and then triisopropyl borate $(3.3 \mathrm{~mL}, 14 \mathrm{mmol})$ was added. The mixture was allowed to warm to room temperature and stirred overnight. The reaction was quenched by water, followed by acidifying with $25 \mathrm{~mL}$ $\mathrm{HCl}(6 \mathrm{M})$. The white precipitate was filtrated, washed by water and dried under vacuum, which was used without further purification.

2,8-Di(1-pyrenyl)-6H,12H-5,11-methanodibenzo[b,f] [1,5]diazocine (TBPy): A two-necked flask was charged with 1-bromopyrene (2.03 g, $7.20 \mathrm{mmol})$, compound 2 (0.93 g, $3.00 \mathrm{mmol}), \mathrm{Pd}\left(\mathrm{PPh}_{3}\right)_{4}$ and well-degassed THF $(60 \mathrm{~mL})$ under $\mathrm{N}_{2}$ atmosphere. After the mixture was stirred for $10 \mathrm{~min}$, sodium carbonate $(30 \mathrm{~mL}, 2 \mathrm{M})$ was added to the flask. The mixture was then allowed to increase to $70^{\circ} \mathrm{C}$ and maintained for $24 \mathrm{~h}$. The solution was extracted with dichloromethane. The organic layer was washed with water and saturated brine and dried over anhydrous $\mathrm{Na}_{2} \mathrm{SO}_{4}$. The solvent was evaporated under reduced pressure and the crude product was purified by flash column chromatography using petroleum/ethyl acetate $(\mathrm{v} / \mathrm{v}=$ 2:1) as eluent to afford a white solid $0.78 \mathrm{~g}$. Yield $41.9 \% .{ }^{1} \mathrm{H}$ NMR ( $\left.\mathrm{CDCl}_{3}, 300 \mathrm{MHz}, \mathrm{ppm}\right), \delta: 4.45$ (d, 2H, $\left.J=16.8 \mathrm{~Hz}\right)$, 4.55 (s, 2H), 4.95 (d, 2H, J = 16.5 Hz), 7.28 (s, 2H), 7.44 (q, $4 \mathrm{H}, J=7.8 \mathrm{~Hz}), 7.94-8.09(\mathrm{~m}, 10 \mathrm{H}), 8.20$ (q, 8H, $J=19.5$ $\mathrm{Hz}) .{ }^{13} \mathrm{C} \mathrm{NMR}\left(\mathrm{CDCl}_{3}, 75.5 \mathrm{MHz}, \mathrm{ppm}\right) \delta: 147.43,137.23$, $137.03,131.51,131.00,130.51,129.81,129.01,128.45$, $128.00,127.61,127.46,127.41,127.39,126.01,125.28$, $125.14,125.10,125.02,124.94,124.81,124.65,67.08,58.83$. MALDI-TOF, m/z: calcd. (\%): 622.2, found (\%): 622.1 .

\section{RESULTS AND DISCUSSION}

Synthesis and characterization: The synthetic strategies and the structure of TBPy are depicted in Scheme-I. Compound 1 was prepared according to the method reported in the literature ${ }^{24}$. The boronic acid moiety of compound $\mathbf{2}$ was introduced by addition of $n$-butyllithium and triisopropyl borate to the THF solution of compound 1 . TBPy were prepared by a palladium-catalyzed Suzuki coupling reaction between pyrene bromide and compound 2 . The final product TBPy was verified by ${ }^{1} \mathrm{H}$ NMR, ${ }^{13} \mathrm{C}$ NMR and MALDI-TOF mass spectrometry.

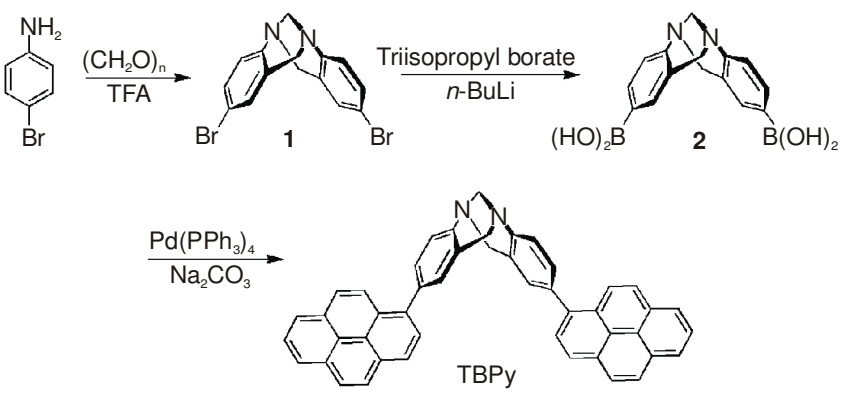

Scheme-I: Synthetic route of TBPy

Photophysical properties: To investigate the photophysical properties, the absorption and photoluminescence spectra of TBPy were measured in dichloromethane $(1.0 \times$ $10^{-6} \mathrm{M}$ ) and in thin film, as shown in Fig. 1. All the corresponding spectral data are summarized in Table-1. TBPy shows two prominent absorption bands with maxima at 279 and 345 $\mathrm{nm}$ in dichloromethane solution. The first absorption band 
TABLE-1

PHYSICAL PROPERTIES OF TBPy

\begin{tabular}{cccccccc}
\hline Compound & $\left.\mathrm{T}_{\mathrm{m}} / \mathrm{T}_{\mathrm{d}}{ }^{\circ}{ }^{\mathrm{C}} \mathrm{C}\right)$ & $\lambda_{\mathrm{ab}}{ }^{\max }(\mathrm{nm})^{\mathrm{a}}$ solution film & $\lambda_{\mathrm{em}}(\mathrm{nm})^{\mathrm{b}}$ solution film & $\mathrm{E}_{\mathrm{g}}{ }^{\text {opt }}(\mathrm{eV})$ & $\mathrm{HOMO}^{(\mathrm{eV})^{\mathrm{c}}}$ & $\mathrm{LUMO}(\mathrm{eV})^{\mathrm{c}}$ \\
\hline TPBy & $304 / 372$ & 345358 & 412464 & 3.13 & -5.36 & -2.23 \\
\hline
\end{tabular}

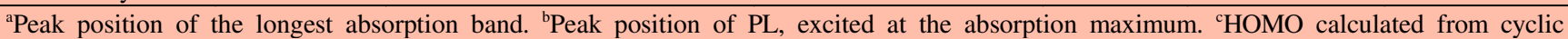
voltammetry potentials using ferrocene as internal standard $\mathrm{HOMO}=-\left(4.80+\mathrm{E}_{\text {onset }}{ }^{o x}-\mathrm{E}_{\mathrm{Fc}}{ }^{o x}\right)$. $\mathrm{E}_{\text {onset }}{ }^{\text {ox }}$ is the onset oxidation potential versus $\mathrm{Ag} / \mathrm{Ag}{ }^{+}$. $\mathrm{E}_{\mathrm{Fc}}{ }^{\text {ox }}$ stands for the onset oxidation potential of ferrocene versus $\mathrm{Ag} / \mathrm{Ag}^{+}$. It is assumed that the redox potential of $\mathrm{Fc} / \mathrm{Fc}^{+}$has an absolute energy level of $-4.80 \mathrm{eV}$ to vacuum.
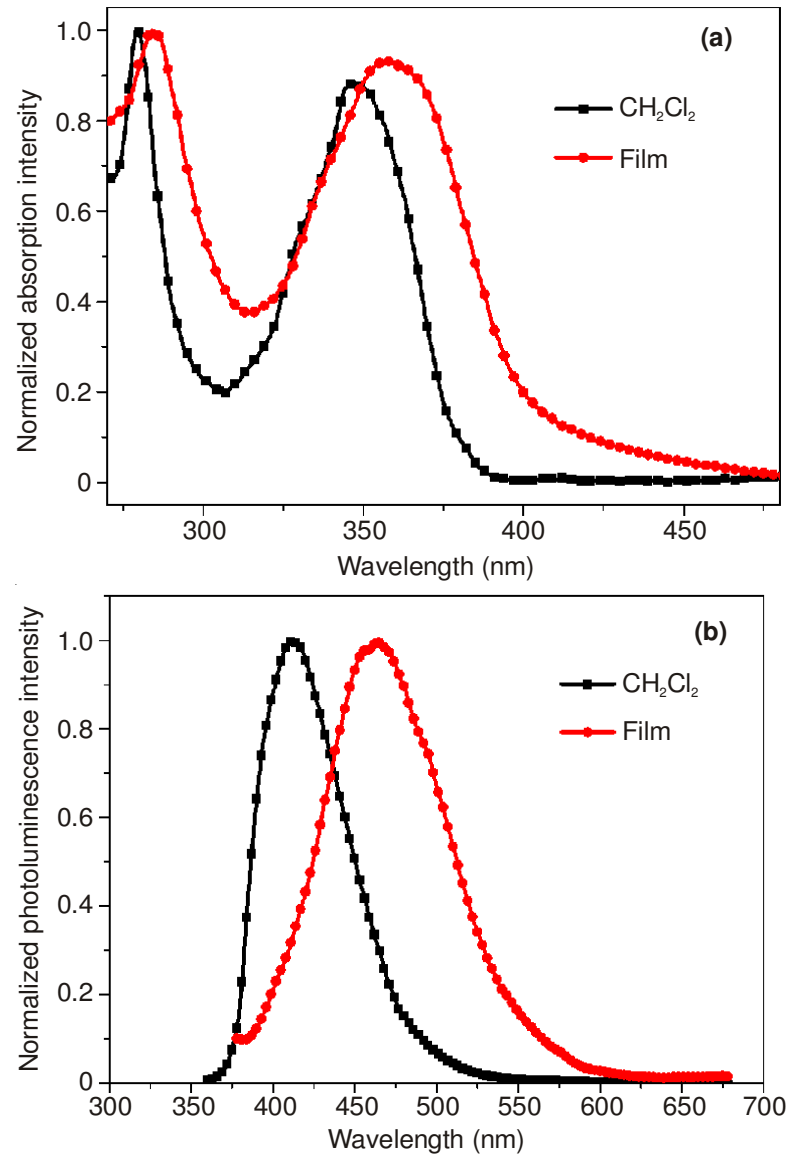

Fig. 1. Normalized UV-visible absorption (a) and photoluminescence (b) spectra of TBPy in dichloromethane solution $\left(1.0 \times 10^{-6} \mathrm{M}\right)$ and in thin film

exhibits the characteristic vibronic pattern of the isolated pyrene group ${ }^{25}$. The second band should be ascribed to the intramolecular $n-\pi *$ transitions. When transfer from solution to film state, the second absorption band of TBPy is red-shifted by $13 \mathrm{~nm}$. The photoluminescence emission spectra of TBPy are also shown in Fig. 1. TBPy shows a blue emission at $412 \mathrm{~nm}$ in dichloromethane with a modest full width at half-maximum (fwhm) value of $64 \mathrm{~nm}$. In thin film state, the photoluminescence emission of TBPy is centered at $464 \mathrm{~nm}$, which represents a $52 \mathrm{~nm}$ bathochromic shift relative to its solution state. The degree of red-shift is less than that of the pyrene monomer ${ }^{26}$. It is manifested that the introduction of Tröger's base framework can effectively hinder the $\pi$ aggregates formation between planar pyrene moieties. In addition, the photoluminescence quantum yield of TBPy in dichloromethane solution was measured by using quinine sulfate as standard. Its solid-state quantum yield was determined by an integrating sphere. The photoluminescence quantum yields of TBPy in dichloromethane solution and solid state are 88.5 and 34.8 , respectively.
Electronic structure: To have a better understanding of the properties of TBPy, calculations on its electronic ground state were carried out using a B3LYP density functional theory with a $6-31 \mathrm{G}(\mathrm{d})$ basis in the Gaussian 09 program $^{27}$. The optimized geometry and electron-density distribution of the highest occupied molecular orbital (HOMO) and lowest unoccupied molecular orbital (LUMO) are shown in Fig. 2. The electron densities of HOMO are averagely distributed on the whole molecule backbone. Though there is some distribution of the LUMO coming from the phenyl rings connected with the pyrene groups, the electron densities of LUMO are mainly localized on the two pyrene rings, indicating that the electronic transitions responsible for the emission of TBPy mainly originate from the $\pi$-orbitals of the pyrene moiety and the nitrogen atoms. Besides, from the optimized geometry of TBPy it can be seen that the two pyrene rings at the ends of TBPy are twisted. The twist angle between the pyrene ring and its adjacent phenyl ring is $53.8^{\circ}$. The two phenyl rings composed of Tröger's base framework are almost perpendicular to each other. These make the molecular structure non-planar, thus facilitating the formation of an amorphous film and reducing the intermolecular $\pi-\pi$ stacking and/or interaction.
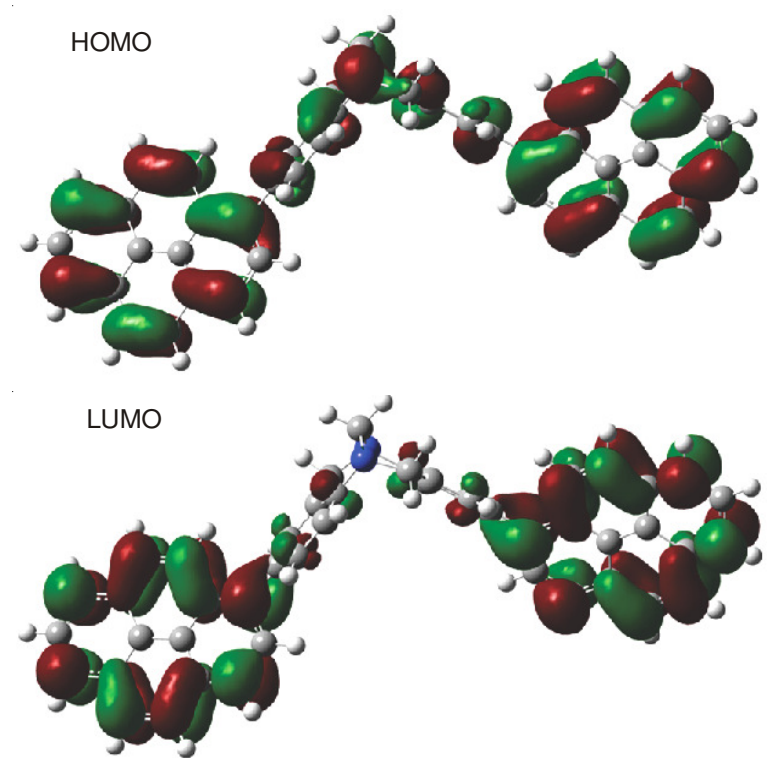

Fig. 2. Molecular orbital surfaces of the HOMO and LUMO of TBPy obtained at B3LYP/6-31G(d) level

Thermal and electrochemical properties: The thermal properties of TBPy were evaluated by DSC and TGA experiments. Key thermal data of the compound are listed in Table1. TBPy exhibits high thermal stability. As shown in Fig. 3, the decomposition temperatures $\left(\mathrm{T}_{\mathrm{d}}\right)$ was found to be $372^{\circ} \mathrm{C}$. In the DSC scan of TBPy, a sharp endothermic peak due to 


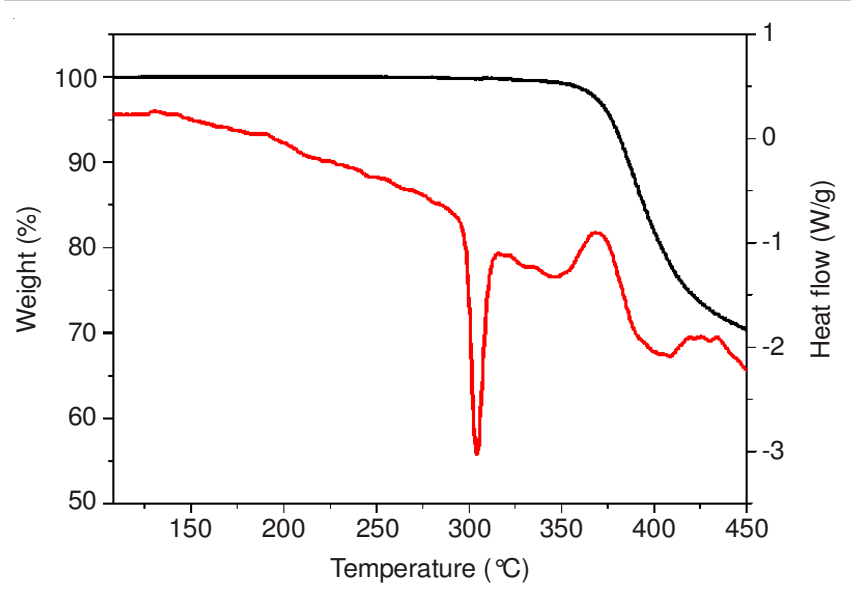

Fig. 3. DSC and TGA scans for TBPy

melting was observed at $304{ }^{\circ} \mathrm{C}\left(\mathrm{T}_{\mathrm{m}}\right)$. The high melting point can extend the operation lifetime of the related OLED. No obvious glass transition phenomenon was detected.

For TBPy used in OLED, it is important to know the energy levels of HOMO and LUMO. Cyclic voltammetry analysis was carried out to identify its electrochemical behaviours and estimate its orbital energies. The orbital energies and band gap are also listed in Table-1. TBPy exhibits three irreversible oxidation peaks and two reversible reduction peaks in dry $\mathrm{CH}_{2} \mathrm{Cl}_{2}$, as shown in Fig. 4. The three oxidation peaks versus $\mathrm{Ag} / \mathrm{Ag}^{+}$are $0.86,1.21$ and $1.71 \mathrm{~V}$, respectively. The onset potential of the first oxidation peak is at $0.64 \mathrm{~V}$. The HOMO energy level is estimated from the onset oxidation potential to be $-5.36 \mathrm{eV}$ using ferrocene as internal standard. Accordingly, the LUMO energy level of TBPy is calculated to be $-2.23 \mathrm{eV}$, by combining the HOMO energy level together with the optical band gap. The HOMO level of TBPy is higher than that of NPB (N,N2-bis(naphthalen-1-yl)-N,N2-bis(phenyl)benzidine, $-5.70 \mathrm{eV})^{28}$, which is one of the most widely used hole-transport materials. So, this material can provide for more facile holeinjection when it is used as an active material in OLED.

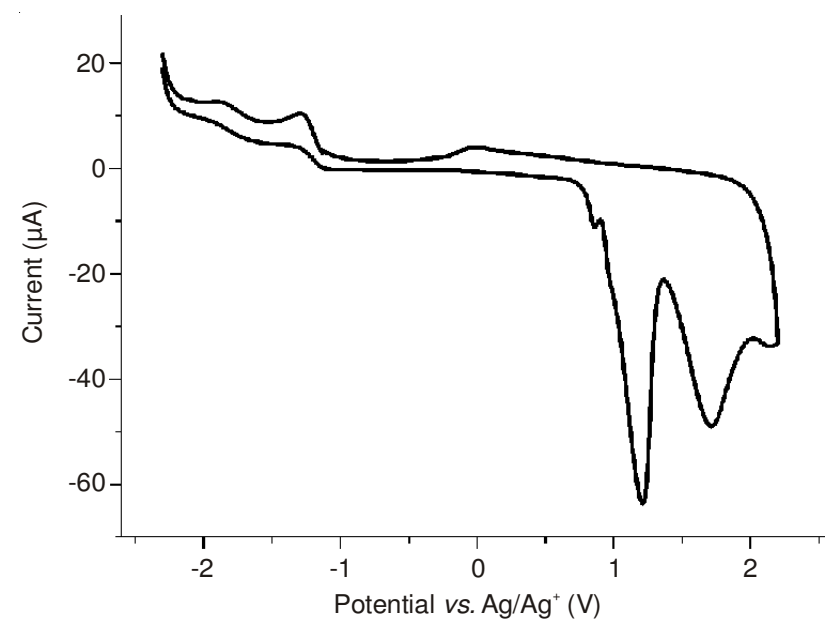

Fig. 4. Cyclic voltammetry of TBPy in dichloromethane

Electroluminescence properties: The device performances based on TBPy were investigated by utilizing it as an emissive layer. The film of TBPy was fabricated by a spin-coating 5 $\mathrm{mg} / \mathrm{mL}$ chloroform solution. The device configuration is ITO/
PEDOT:PSS (50 nm)/TBPy (50 nm)/TPBI (15 nm)/LiF(1 nm)/ $\mathrm{Al}(80 \mathrm{~nm})$. In the device, ITO (indium tin oxide) is the anode, PEDOT:PSS (poly(3,4-ethylenedioxythiophene) and poly(styrenesulfonate)) serves as the hole-transporting layer of the OLED device, TPBI [1,3,5-tri(1-phenyl-1H-benzo[d]imidazol2-yl)phenyl] as an electron-transporting layer and a hole blocker and LiF:Al as the composite cathode. Fig. 5 shows the normalized electroluminescent emission spectra of the diode based on TBPy. The device exhibits a blue emission at $485 \mathrm{~nm}$. No obvious changes are observed in the electroluminescent spectra upon being operated from 13-18 V. Additionally, the shape of electroluminescent spectra resembles to that of the corresponding solid-state photoluminescence spectrum with a slight red shift. This indicates that both photoluminescence and electroluminescent of TBPy originate from the same radiative-decay process of the single excitons. Therefore, it is a promising candidate for fabricating efficient OLEDs.

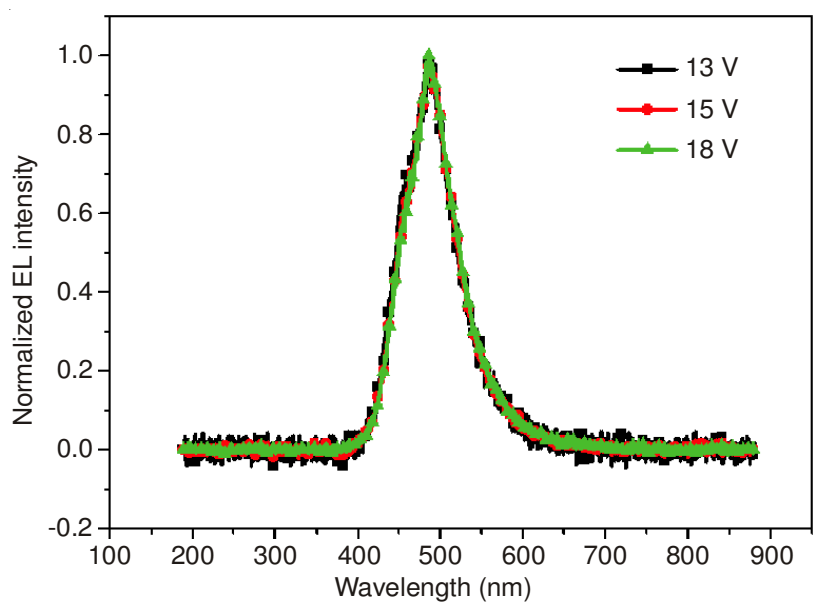

Fig. 5. Electroluminescent spectra of the device based on TBPy

\section{Conclusion}

We have synthesized a novel pyrene derivative based on Tröger's base by Suzuki reaction. Its photophysical, thermal, electrochemical and electroluminescent properties as well as the electronic structure were investigated. TBPy possess high thermal stability. The results from photoluminescence measurements and electronic structure indicate that the commonly observed aggregate/exicimer of the pyrene monomer is effectively suppressed in TBPy compound. The cyclic voltammetry measurement reveals that TBPy has high hole-transport ability. The electroluminescent device with TBPy functioning as an emitting material was fabricated. The device exhibits a blue emission at $485 \mathrm{~nm}$. The excellent thermal stability and the good capability of emitting and hole-transport will make TBPy a promising candidate.

\section{ACKNOWLEDGEMENTS}

This work was supported by National Natural Science Foundation of China (Grant No. 51021062, 50990061, 51273141), the Natural Science Foundation of JiangSu Province Education Committee (11KJA430003), Project of Person with Ability of Jiangsu Province (2010-xcl-015), the Priority Academic Program Development of Jiangsu Higher Education 
Institutions (PAPD) and the Opening Project of Key Lab of Advanced Optical Manufacturing Technologies of Jiangsu Province (KJS1102) and the Project of Suzhou University of Science and Technology (XKQ201312).

\section{REFERENCES}

1. C.W. Tang and S.A. VanSlyke, Appl. Phys. Lett., 51, 913 (1987).

2. J.H. Burroughes, D.D.C. Bradley, A.R. Brown, R.N. Marks, K. Mackay, R.H. Friend, P.L. Burns and A.B. Holmes, Nature, 347, 539 (1990).

3. R.H. Friend, R.W. Gymer, A.B. Holmes, J.H. Burroughes, R.N. Marks, C. Taliani, D.D.C. Bradley, D.A.D. Santos, J.L. Brdas, M. Lgdlund and W.R. Salaneck, Nature, 397, 121 (1999).

4. B.W. D'Andrade and S.R. Forrest, Adv. Mater., 16, 1585 (2004).

5. L. Duan, L.D. Hou, T.W. Lee, J. Qiao, D.Q. Zhang, G.F. Dong, L.D. Wang and Y. Qiu, J. Mater. Chem., 20, 6392 (2010).

6. K.H. Lee, C.S. Son, J.Y. Lee, S. Kang, K.S. Yook, S.O. Jeon, J.Y. Lee and S.S. Yoon, Eur. J. Org. Chem., 4788 (2011).

7. J.R. Lakowicz, Principles of Fluorescence Spectroscopy, Plenum, New York (1999).

8. N. Karl, Synth. Met., 133-134, 649 (2003).

9. L. Zöphel, D. Beckmann, V. Enkelmann, D. Chercka, R. Rieger and K. Müllen, Chem. Commun., 47, 6960 (2011).

10. K.A. Zachariasse, Trends Photochem. Photobiol., 3, 211 (1994).

11. Z.Q. Liang, Z.Z. Chu, D.C. Zou, X.M. Wang and X.T. Tao, Org. Electron., 13, 2898 (2012).

12. C. Poriel, N. Cocherel, J. Rault-Berthelot, L. Vignau and O. Jeannin, Chem. Eur. J., 17, 12631 (2011).

13. X.M. Liu, C.B. He, J.C. Huang and J.M. Xu, Chem. Mater., 17, 434 (2005).

14. T.M. Figueira-Duarte, P.G. Del Rosso, R. Trattnig, S. Sax, E.J.W. List and K. Müllen, Adv. Mater., 22, 990 (2010).

15. J. Tröger, J. Prakt. Chem., 36, 225 (1887).

16. A. Tatibouët, M. Demeunynck, C. Andraud, A. Collet and J. Lhomme, Chem. Commun. (Camb.), 23, 161 (1999).
17. Y. Kubo, T. Ohno, J.- Yamanaka, S. Tokita, T. Iida and Y. Ishimaru, J. Am. Chem. Soc., 123, 12700 (2001).

18. N.R. Deprez, K.A. McNitt, M.E. Petersen, R.G. Brown and D.E. Lewis, Tetrahedron Lett., 46, 2149 (2005).

19. C.L. Ramírez, R. Procaccini, C.A. Chesta, A.R. Parise and D.M.A. Vera, Org. Electron., 14, 2564 (2013)

20. C.X. Yuan, Q. Xin, H.J. Liu, L. Wang, M.H. Jiang and X.T. Tao, Sci. China Chem., 54, 587 (2011)

21. Q. Xin, X.-T. Tao, F.-Z. Wang, J.-L. Sun, D.-C. Zou, F.-J. Wang, H.-J. Liu, Z. Liu, Y. Ren and M.-H. Jiang, Org. Electron., 9, 1076 (2008).

22. C.X. Yuan, X.T. Tao, Y. Ren, Y. Li, J.X. Yang, W.T. Yu, L. Wang and M.H. Jiang, J. Phys. Chem. C, 111, 12811 (2007).

23. H. Xi, C.X. Yuan, Y.X. Li, Y. Liu and X.T. Tao, CrystEngComm, 14, 2087 (2012).

24. J. Jensen, M. Strozyk and K. Wärnmark, J. Heterocycl. Chem., 40, 373 (2003).

25. J.Y. Hu, M.M. Era, R.J. Elsegood and T. Yamato, Eur. J. Org. Chem., 72 (2010).

26. K.C. Wu, P.J. Ku, C.S. Lin, H.T. Shih, F.I. Wu, M.J. Huang, J.J. Lin, I.C. Chen and C.H. Cheng, Adv. Funct. Mater., 18, 67 (2008).

27. M.J. Frisch, G.W. Trucks, H.B. Schlegel, G.E. Scuseria, M.A. Robb, J.R. Cheeseman, G. Scalmani, V. Barone, B. Mennucci, G.A. Petersson, H. Nakatsuji, M. Caricato, X. Li, H.P. Hratchian, A.F. Izmaylov, J. Bloino, G. Zheng, J.L. Sonnenberg, M. Hada, M. Ehara, K. Toyota, R. Fu-kuda, J. Hasegawa, M. Ishida, T. Nakajima, Y. Honda, O. Kitao, H. Nakai, T. Vreven and J.A. Montgomery Jr., J.E. Peralta, F. Ogliaro, M. Bearpark, J.J. Heyd, E. Brothers, K.N. Kudin, V.N. Staroverov, R. Kobayashi, J. Normand, K. Raghavachari, A. Rendell, J.C. Burant, S.S. Iyengar, J. Tomasi, M. Cossi, N. Rega, J.M. Millam, M. Klene, J.E. Knox, J.B. Cross, V. Bakken, C. Adamo, J. Jaramillo, R. Gomperts, R.E. Stratmann, O. Yazyev, A.J. Austin, R. Cammi, C. Pomelli, J.W. Ochterski, R.L. Martin, K. Morokuma, V.G. Zakrzewski, G.A. Voth, P. Salvador, J.J. Dannenberg, S. Dapprich, A.D. Daniels, O. Farkas, J.B. Foresman, J.V. Ortiz, J. Cioslowski, D.J. Fox, Gaussian 09, Revision A.02, Gaussian, Inc., Wallingford CT, (2009).

28. J.G.C. Veinot and T.J. Marks, Acc. Chem. Res., 38, 632 (2005) 